\title{
TP53 promoter methylation in EBV and HPV associated oropharyngeal carcinoma - a pilot study
}

\author{
Adrian Jarzynski*, Anastazja Boguszewska, Ewa Kliszczewska, \\ Lukasz Rolniak, Anna Dworzanska, Malgorzata Polz-Dacewicz
}

Department of Virology, Medical University of Lublin, Chodzki 1, 20-093 Lublin, Poland

\begin{tabular}{|c|c|}
\hline ARTICLE INFO & ABSTRACT \\
\hline Received 26 June 2017 & \multirow{6}{*}{$\begin{array}{l}\text { TP } 53 \text { promoter methylation was examined in frozen tumor tissue taken from patients with } \\
\text { oropharyngeal carcinoma with EBV, HPV and co-infection EBV/HPV. This pilot study } \\
\text { was performed on } 48 \text { patients. Initial studies indicate a high frequency of methylation } \\
\text { in HPV-associated ( } 57.1 \%) \text { and EBV - associated OSCC }(60 \%) \text { cases, whilst the highest } \\
\text { exists in co-infection HPV/EBV }(75 \%) \text {. Future studies on a larger group of patients, of the } \\
\text { mechanisms of co-infection and their role in oral squamous cell carcinoma, are necessary. }\end{array}$} \\
\hline Accepted 29 July 2017 & \\
\hline Keywords: & \\
\hline TP53, & \\
\hline methylation, & \\
\hline & \\
\hline
\end{tabular}

\section{INTRODUCTION}

Head and neck cancers are a very important public health problem in Poland and worldwide. Herein, squamous cell carcinoma (SCC) constitutes $90 \%$ of all cases of cancers localised in the oral cavity and the oropharynx (OSCC). The etiology of OSCC is considered to be multifactorial, and oncogenic viruses are known to be involved in OSCC development [10]. Studies on the cancerogenecity of HPV in humans were conducted by the International Agency for Research on Cancer (IARC). Accordingly, 10-30\% of oral cancers are associated with HPV, while a number of other studies suggest, the participation of Epstein-Barr virus (EBV), as well, in oral cancer. This is one of the most common viruses in humans, hence, it is classified as group 1 carcinogen by the World Health Organization's International Agency for Research on Cancer [1,11].

Currently, epigenetics has been the most rapidly expanding field in biological sciences. Epigenetic instability is a change in the expression of genes that is not directly linked with the DNA sequence. Methylation occurs primarily during the $\mathrm{S}$ phase of the cell cycle and is based on the covalent attachment of methyl groups (-CH3) to the nitrogenous nucleobases (around $\mathrm{CpG}$ dinucleotide). In the human genome, approximately $70 \%$ of $\mathrm{CpG}$ islands have a methyl group attached to the cytosine, however, this process does not occur in areas essential for the basic processes of the cell. This includes the $\mathrm{CpG}$ island located at the 5' ends of the promoter regions of genes. Of note, gene silencing through promoter methylation is an important risk factor in

\footnotetext{
* Corresponding author

e-mail: a.jarzynski87@gmail.com
}

the development of different cancers. Indeed, methylation of the TP53 promoter region has been reported in several tumors [8].

The aim of our study was to analyze in Polish patients, the frequency of TP53 promoter methylation in EBVpositive, HPV-positive and in co-infected orapharyngeal squamous cell carcinoma.

\section{MATERIAL AND METHODS}

\section{Patients}

The present study comprised a group of 48 patients with a diagnosed and histopathologically confirmed OSCC who were hospitalized at the Otolaryngology Division Hospital in Radom, Poland. The patients had neither previous radiotherapy nor chemotherapy.

TNM classification was carried out according to the criteria of the Union Against Cancer (UICC). Histological grading was performed according to WHO criteria [6] (G1: well-differentiated, G2: moderately well-differentiated, G3: poorly differentiated).

This research was approved by the Ethics Committee and is in accordance with the GCP regulations (no. KE-0254/181/2012).

The epidemiological, clinical and pathological characteristics of the studied patients are shown in Table 1. Male patients dominated in the examined group $(91.7 \%)$. The patients' age ranged from 40 to 79 years, and the most numerous group was composed of patients aged 50-69 years $(56.3 \%)$, with only $16.7 \%$ of all patients being under 50 years of age. Most studied individuals (77.1\%) lived in 
urban areas. A total of $81.3 \%$ of the studied patients reported smoking, while $89.6 \%$ reported alcohol abuse. Patients with stage G2 (63.8\%), T2 (37.5\%) and N1 (43.8\%) disease prevailed. All patients had stage M0 disease (i.e. no spread to other organs).

\section{DNA extraction}

The material consisted of 48 fresh frozen tumor tissue fragments taken from the aforementioned OSCC patients. Fragments of fresh tissue $(20 \mathrm{mg})$ were cut and homogenized in an Omni TH manual homogenizer (Omni International, Kenneswa, Georgia, USA) and then subjected to isolation of the genetic material through employing the QIAamp DNA Minikit (Qiagen, Hilden, Germany) according to the manufacturer's instruction. Immediately after the isolation, the efficiency and purity of the obtained eluate was assessed by way of an Epoch spectrophotometer (Biotek Instruments, Winooski, Vermont, USA). The measurement was performed on a Take 3 plate (Biotek Instruments, Winooski, Vermont, USA), which enables the measurement in micro-volumes $(2 \mu 1)$. A Microplate Reader Software Gen 5.2.0 (Biotek Instruments, Winooski, Vermont, USA) was used to analyze the results. The isolates were kept at $-20^{\circ} \mathrm{C}$ until the test was conducted. To verify the quality of the obtained DNA (the presence of Polymerase Chain Reaction inhibitors), a $\beta$-globin assay was performed.

\section{Detection of viruses}

Nested PCR was carried out for the detection of EBV DNA. PCR reactions were undertaken in the final volume of $25 \mu$ l, using a Taq PCR Core Kit (Qiagen, Hilden, Germany). The primer sequences are outer: 5'-GTC ATC TAC GGG GAC ACG GA-3' and 5'-AAG AAG AGA TAT GTG GGG GT-3'; Inner: 5' - ACC CGG AGC CTG TTT GTG GC-3' and 5'-GGA GAA GGT CTT CTC GGC CTC-3'. The PCR product had $54 \mathrm{bp}$. Concentrations of $\mathrm{PCR}$ reaction components were prepared as follows: $2 \mathrm{mM} \mathrm{MgCl}$, $0.2 \mathrm{mM}$ dNTPs, $0.2 \mu \mathrm{M}$ each forward and reverse primers, and $0.5 \mathrm{U}$ of Taq DNA polymerase. During each run, the samples were analyzed together with one negative and positive control. Negative control was nuclease-free water, positive control - EBV-positive cell line, Namalwa, ATCC-CRL-1432. The reaction mixture, containing $5 \mu \mathrm{l}$ of extracted DNA, was amplified under the following conditions: $94^{\circ} \mathrm{C}$ for 3 minutes of initial denaturation, then 35 cycles of $94^{\circ} \mathrm{C}$ for 30 seconds, $55^{\circ} \mathrm{C}$ for 40 seconds, $72^{\circ} \mathrm{C}$ for 1 minute, with the final extension at $72^{\circ} \mathrm{C}$ for 5 minutes. The second round amplification was performed with $1 \mu \mathrm{l}$ of the first run product in the same conditions. The final PCR products were analyzed on $3 \%$ agarose gel.

HPV detection and genotyping was performed using the INNO-LiPA HPV Genotyping Extra-assay (Innogenetics, Gent, Belgium). The kit is based on the amplification of a $65 \mathrm{bp}$ fragment from the L1 region of the HPV genome utilizing a SPF10 primer set. PCR products are subsequently typed with the reverse hybridization assay.

\section{Bisulfite modification of the DNA samples}

Sodium bisulfite modification was performed using the CpGenome Turbo Bisulfite Modification Kit (Milipore,
Merck KGaA, Darmstadt, Germany, catalog no S7847) according to the manufacturer's protocol. The converted DNA was eluted and stored at $-20^{\circ} \mathrm{C}$ for further studies. The bisulfite-treated DNA was used as template for methylationspecific PCR (MSP).

\section{Methylation-specific PCR (MSP)}

Methylation was done via the MSP method described by Herman at al. [9] and Bahtia et al. [4]. Bisulfite modified DNA was amplified with p53 gene-specific primers for methylated and unmethylated sequences: methylated: (forward) - 5'-TTCGGTAGGCGGATTATTTG-3' (reverse) - 5'-AAATATCCCCGAAACCCAAC-3' and unmethylated: (forward) - 5'-TTGGTAGGTGGATTATTTGTTT-3', (reverse) - 5'CCAATCCAAAAAAACATATCAC-3'. Primer pairs were purchased from Genomed, (Warsaw, Poland). Before examining the clinical samples, optimization of the reaction conditions and starters compatibility was performed using human total methylated and unmethylated DNA (CpGenome Human Methylated DNA, Milipore, Darmstadt, Germany).

Nested PCR was performed to analyze the promotor methylation status of the p53 gene. PCR amplification was carried out (in duplicate for each primer pairs) in a $25 \mu \mathrm{l}$ mixture containing: water $-17.5 \mu \mathrm{l}$; buffer do PCR 10× $-2.5 \mu \mathrm{l} ; \mathrm{MgCl}_{2}-0.5 \mu \mathrm{l}$; dNTP $-0.5 \mu \mathrm{l}$; starter forward (each for reaction) $0.5 \mu \mathrm{l}$; starter reverse (each for reaction) $0.5 \mu \mathrm{l}$; polymerase Taq DNA (Qiagen) $0.125 \mu \mathrm{l}$; bisulfitemodified DNA $3 \mu \mathrm{l}$. The reaction was heated at $94^{\circ} \mathrm{C}$ for 3 minutes and then amplified for 45 cycles $\left(94^{\circ} \mathrm{C} / 45\right.$ seconds, $55^{\circ} \mathrm{C} / 45$ seconds and $72^{\circ} \mathrm{C} / 1$ minute), followed by a final 5 -minute extension at $72^{\circ} \mathrm{C}$. The final PCR products were analyzed on $2 \%$ agarose gel with ethidium bromide, and visualized under ultraviolet light. The PCR product for the unmethylated reaction was $247 \mathrm{bp}$, and for the methylated reaction - 193bp (Figure 1).

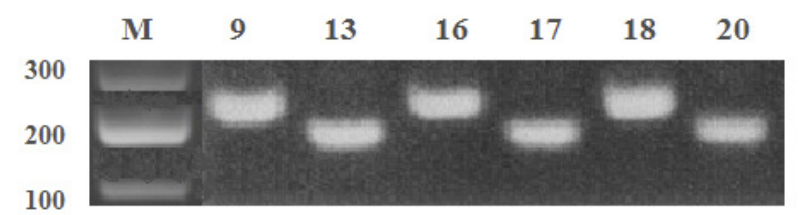

Figure 1. Electrophoresis results for p53 promoter MSP products. [M] - DNA length marker 100-500bp (DNA Gdansk); [9,13,16, $17,18,20]$ - sample numbers. For methylated sequence product has length 193bp, for unmethylated sequence product has length $247 \mathrm{bp}$

\section{Statistical analysis}

Statistical analysis was performed to investigate the relationship between EBV and HPV presence and the methylation of $\mathrm{p} 53$ and clinical parameters, by means of Pearson's chi-square test. Statistical significance was defined as $p<0.05$.

\section{RESULTS}

EBV was detected in $42.0 \%$ of all cases, HPV in $29.0 \%$ and co-infection EBV/HPV in $8.0 \%$ of the whole studied 
group (Figure 2). The frequency of TP53 promoter methylation is shown in Fig. 3. The highest frequency was detected in co-infection $\mathrm{HPV} / \mathrm{EBV}-75 \%$ of all cases. However, no correlation was observed between the histopathological grade and the frequency of TP53 promoter methylation.

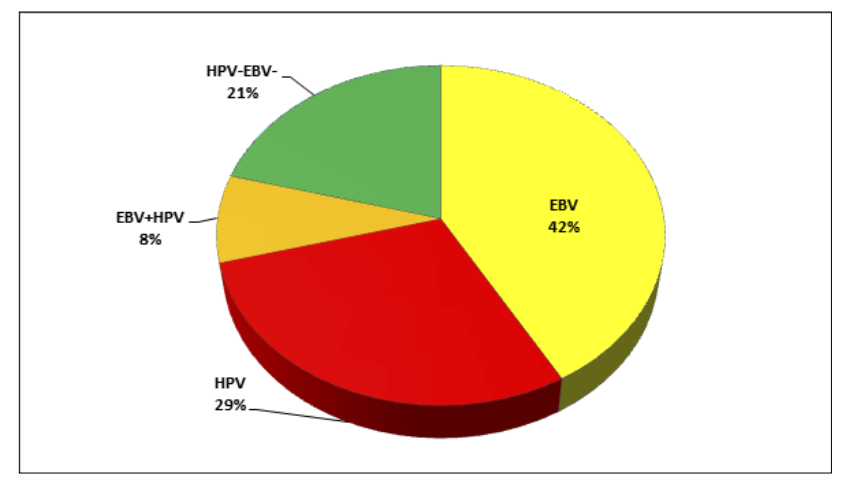

Figure 2. Prevalence of HPV, EBV and coinfection HPV/EBV in oropharyngeal cancer

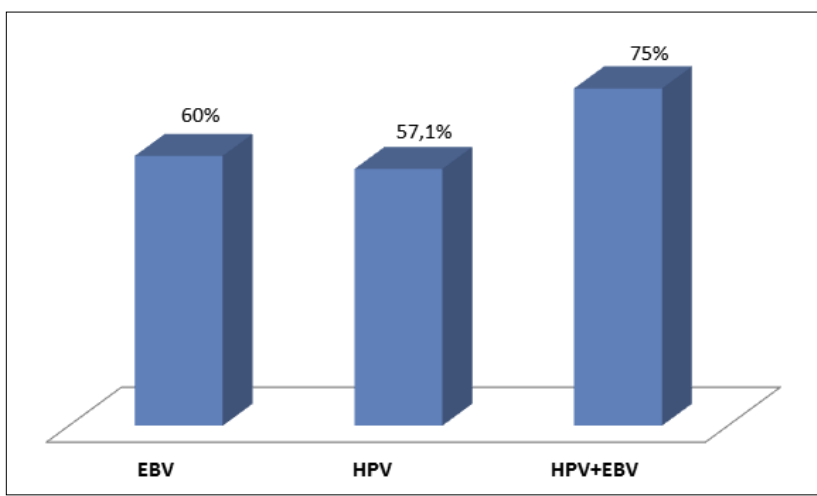

Figure 3. Frequency of TP53 promoter methylation in EBV-, $\mathrm{HPV}$-related and coinfection EBV/HPV in orpharyngeal cancer

\section{DISCUSSION}

Methylation of DNA is an epigenetic modification and can occur at sites where cytosine is followed by guanine. DNA methylation, particularly in promoter regions, is known to silence the expression of associated genes and may occur even more frequently than inactivation of genes by mutation [19]. A correlation between the epigenetic changes of gene expression and oral cancer progression is, however, not fully demonstrated [14].

Most cancer-associated infectious agents, including viruses, can be divided into two categories, namely indirect and direct carcinogens. Indirect carcinogens cause cancer through the chronic infection and inflammation that leads to carcinogenic mutations of the host cells. Chronic inflammation is a prolonged exposure to inflammatory mediators such as free radicals, prostaglandins, and cytokines. It can cause DNA damage and oncogenic mutations in the host [7]. HPV and EBV are considered direct carcinogens because they express viral oncogenes which can directly transform host cells. During direct oncogenesis, some of or the whole viral genome integrates with the host genome and modifies the proliferation and survival pathways within the host cell. The methylation of tumor suppressor genes in OSCC is well documented [13].
DNA methylation patterns can be used as a biomarker for early diagnosis, as well as for classification, prognosis and therapy of human cancers. The promotor methylation has been found in a wide variety of genes which are involved in cell cycle, apoptosis, cell-cell adhesion, migration, invasion and metastasis [15].

The TP53 gene maps on chromosome 17p13.1 and encodes a tumor suppressor protein, also called p53, which takes a major role in genomic stability, cell cycle progression, cellular differentiation, DNA-repair and apoptosis. The p53 gene introduces G1 arrest in the cell cycle to allow the repair of DNA damage and prevent the cell from entering the $\mathrm{S}$ phase. Silencing of methylated genes can affect the prognosis for patients with laryngeal and hypopharyngeal cancer [3]. In our study, the total frequency of the TP53 promoter methylation was identified in $57.1 \%$ of all cases.

Many studies have explored the differences in methylation profiles between HPV positive and HPV negative head and neck cancers, and genome-wide methylation differences between these two classes were previously noted in squamous cell carcinoma cell lines [14]. The oncogenic potential of HPV is related to the expression of E6 and E7. The human papillomavirus oncoprotein E6 and E7 promote carcinogenesis by degrading the p53 tumor suppressors, but in HPV-negative cancers, SCC is not degraded, yet it is frequently mutated. From the molecular point of view, high risk HPV positive tumors are characterized by high genomic instability, due to a dysregulation of the cell cycle control epigenetically induced by the E6 and E7 HR-HPV oncoproteins [20].

EBV is widespread in the world's population (about $90 \%$ ). Indeed, it is the first virus wholly associated with a human cancer. Primary EBV infection is acquired at a young age and involves salivary transmission of the virus to the oropharynx and probable entry through the tonsils, where the virus targets B lymphocytes for lytic and latent infection. The oral cavity is a persistent reservoir for Epstein-Barr virus with lifelong infection. In addition, the virus can reactivate periodically without symptoms and can be found in the saliva of infected individuals. A number of authors emphasize the role of EBV in the development of OSCC [2,11,12]. Most EBV-associated malignancies occur many years after the first infection, and are associated with latent infection.

All EBV latency genes have been implicated either in cell transformation, mostly accompanied by $\mathrm{Cp}$-on latency, or in oncogenesis that is primarily accompanied by Cp-off latency [16]. An analysis of global cellular DNA methylation detected over 13,000 differentially methylated $\mathrm{CpG}$ residues in cells exposed to EBV. The oncogenic potential of EBV is related to the expression of LMP-1 and LMP-2. TP53 methylation in our studied group was detected in $60 \%$ of all EBV positive cases [5].

Many studies indicate a co-infection with HPV and EBV. This could be involved in the neoplastic transformation of the oral epithelium and may be an important risk factor in the development of OSCC [12]. Co-infected cells can have a higher tumorigenic potential than normal cells, and coinfection of both HPV and EBV may have a more profound effect on invasion than on proliferation. Recent studies have 
examined the association between EBV and high-risk strains of HPV in the progression of human oral cancers. In these, it has been established that approximately $38 \%$ of all human nasopharyngeal carcinomas are associated with high-risk HPV and EBV co-infections, still the mechanism of carcinogenesis is not yet understood. Some studies hypothesize, however, that HPV oncoproteins E6/E7 cooperate with the EBNA1, LMP1, LMP2, and BARF1 EBV oncoproteins to transform the oral epithelium [2]. Indeed, our studies show that in co-infected tissue samples, the frequency of methylation was higher than in infections by a single virus $(75 \%$ of all samples).

Methylation of the promotor regions is an important mechanism for silencing the genes at early stages of carcerogenesis, hence it can be an important prognostic factor [18]. In our work, the differences in the frequency of methylation in EBV-positive and HPV positive were not statistically significant, probably due to the small size of the group. However, these preliminary studies point to the high frequency of methylation in HPV-associated and EBV - associated OSCC cases, as well as in co-infection. Moreover, such biomarkers reveal genetic and molecular changes related to early, intermediate, and late end points in the process of oral carcinogenesis [17].

In conclusion, the results of the current pilot study confirmed that methylation of the p53 gene is frequent in oropharyngeal cancers associated with EBV and HPV infection alone, as well as in HPV/EBV co-infection. Future studies are, however, necessary in a larger group of patients on the mechanisms of co-infection and its role in oral squamous cell carcinoma. When fully understood, biomarkers such as methylation may provide help in the evaluation of prevention, in target therapy and in the development of diagnostic methods, of the earliest stages of oral mucosal tumor transformation.

\section{Conflict of interest statement: none declared}

Acknowledgements: This study was supported by a Research Grant from the Medical University, Lublin, Poland (DS 233).

\section{REFERENCES}

1. Acharya S., Ekalaksananan T., Vatanasapt P., Loyha K., Phusingha P., Promthet S., Kongyingyoes B., Pientong C.: Association of EpsteinBarr virus infection with oral squamous cell carcinoma in a casecontrol study. J. Oral. Pathol. Med., 43, 7, 2014.

2. Al Moustafa A. E., Chen D., Ghabreau L., Akil N.: Association between human papillomavirus and Epstein-Barr virus infections in human oral carcinogenesis. Med. Hypotheses, 73, 2, 2009.

3. Arantes L.M., De Caravallo A. C., Melendez M.E., Carvalho A.L., Goloni-Bertollo E.M.: Methylation as biomarker for head and neck cancer. Oral Oncol., 50, 6, 2014.
4. 4. Bhatia V., Goel M.M., Makker A., Tewari S., Yadu A., Shilpi P., Kumar S., Agarwal S.P., Goel S.K.: Promoter Region Hypermethylation and mRNA Expression of MGMT and p16 Genes in Tissue and Blood Samples of Human Premalignant Oral Lesions and Oral Squamous Cell Carcinoma. Bio. Med. Research International, 2014.

5. Birdwell C.E., Queen K.J., Kilgore P.C.: Genome-wide DNA methylation as an epigenetic consequence of Epstein-Barr virus infection of immortalized keratinocytes. J. Virol, 88, 19, 2014.

6. Cardesa A., Gale N., Nadal A., Zidor N.: Squamous cell carcinoma in World Health Organization Classifiation of Tumours. Pathology and Genetics: Head and Neck Tumours. Barnes L., Eveson J.W., Reichart P., Sidnousky, Lyon, International Agency for Research on Cancer, 2010.

7. Franks A.L., Slansky J.E.: Multiple associations between a broad spectrum of autoimmune diseases, chronic inflammatory diseases and cancer, Anticancer Res. 32, 4, 2012.

8. González-Ramírez I., García-Cuella C., Sánchez-Pérez Y., GranadosGarcía M.: DNA methylation in oral squamous cell carcinoma: molecular mechanisms and clinical implications. Oral Dis.,17, 8, 2011.

9. Herman J.G., Graff G.R., Myöhänen S., Nelkin B. D., Baylin S.B.: Methylation-specific PCR: a novel PCR assay for methylation status of CpG islands. Proc. Natl. Acad. Sci. 93, 18, 1996.

10. Hillbertz N.S., Hirsch J.M., Jalouli J., Jalouli M., Sand L.: Viral and molecular aspects of oral cancer. Anticancer Res., 32, 10, 2012.

11. Jalouli J., Jalouli. M., Sapkota D., Ibrahim S.O., Larsson P.A., Sand L.: Human papilloma virus, herpes simplex and Epstein-Barr virus in oral squamous cell carcinoma from eight different countries. Anticancer Res. 32, 2, 2012.

12. Jiang R., Ekshyyan O., Moore-Medlin T., Rong X., Nathan S., Gu X., Abreo F., Rosenthal E.L., Shi M., Guidry J.T., Scott R.S., HuttFletcher L.M., Nathan C.A..: Association between human papilloma virus/Epstein-Barr virus co-infection and oral carcinogenesis. J. Oral Pathol. Med., 44, 1, 2015.

13. Jithesh P.V., Risk J.M., Schache A.G., Dhanda J., Lane B., Liloglou T., Shaw R.J.: The epigenetic landscape of oral squamous cell carcinoma. Br. J. Canc., 108, 2, 2013.

14. Mascolo M., Siano M., Ilardi G., Russo D., Merolla F., De Rosa G., Staibano S. Epigenetic disregulation in oral cancer. Int. J. Mol. Sci.,13, 2, 2012.

15. Mund C., Lyko F.: Epigenetic cancer therapy: Proof of concept and remaining challenges. Bioassays, 32, 11, 2010.

16. Takacs M., Banati F., Koroknai A., Segesdi J., Salamon D., Wolf H., Niller H.H., Minarovits J.: Epigenetic regulation of latent EpsteinBarr virus promoters. Biochem. Biophysic Acta, 1799, 4, 2010.

17. Tanaka T., Ishigamori R.: Understanding Carcinogenesis for Fighting Oral Cancer J. Oncology, 2011

18. Towle R., Troung D., Kirsten Hogg K.: Global analysis of DNA methylation changes during progression of oral cancer Oral Oncology, 49, 11, 2013.

19. Van Kempen P. M., Braunius R., Stegeman I., Willems S.M., Grolman W.: Differences in methylation profiles between HPV-positive and HPV-negative oropharynx squamous cell carcinoma: a systematic review. Epigenetics, 9, 2, 2014.

20. Wiest T., Schwarz E., Enders C., Flechtenmacher C., Bosch F.X.: Involvement of intact HPV16 E6/E7 gene expression in head and neck cancers with unaltered p53 status and perturbed pRb cell cycle control. Oncogene, 21, 10, 2002. 